\title{
Applying Differentiated Instruction in Elementary Classrooms: Practice and Reflection of Student Teachers
}

\author{
Ping Liu \\ College of Education, California State University Long Beach, 1250 Bellflower Blvd., \\ Long Beach CA 90840-2201, U.S.A. \\ E-mail of the corresponding author: Ping.Liu@csulb.edu
}

\begin{abstract}
Differentiated instruction has a direct impact on the quality of teaching in inclusive classrooms. For student teachers, their ability to plan and apply differentiation is a factor in transformation from a dependent to an independent teacher. This study examines student teachers' practice of differentiated instruction to meet diverse needs of elementary students including English learners. The participants completed a survey, planned and taught lessons, and wrote summative reflection on areas to improve after student teaching. The results indicated that the group preferred to use some strategies more than others to differentiate instruction. However, application of the same strategies varied in how instructional activities were organized and level of student participation. Analysis of the after student teaching summative reflection revealed a focus on assessments of student learning. The student teachers would like to further develop in differentiation by exploring assessments not only from a teacher perspective but also through student self-assessment to promote active participation and self-directed learning. The findings indicated that the participants recognized the importance of comprehensive assessments in applying differentiation to support students of diverse needs as a result of completing student teaching. Implications for teacher preparation are also discussed.
\end{abstract}

Keywords: differentiated instruction, student teaching, elementary level, English learners

DOI: $10.7176 / \mathrm{JEP} / 12-27-01$

Publication date:September $30^{\text {th }} 2021$

\section{Introduction}

Differentiated instruction (DI) is an instructional approach, responding to academic needs of learners through differentiation of instruction with on-going assessment and flexible grouping (Hall, 2002; Taylor, 2017; Tomlinson, 2014). Differentiation can find its theoretical foundation in brain research related to student academic readiness skills (Tomlinson \& Kalbfleisch, 1998) and multiple intelligence theory with recognition of different kinds of intellectual abilities (Gardner, 1999). Differentiated instruction is also grounded in constructivism or zone of proximal development (Vygotsky, 1978), wherein students are able to tackle challenging tasks with appropriate support of more capable others. Teachers can provide guidance and support to maximize student learning when they make instructional decisions in content, process, products, or learning environment (Tomlinson, 2014). It is a complex process to apply differentiated instruction (Smets, 2017; Tomlinson, 1999) with many factors involved in a given context.

In inclusive classrooms, students have a variety of needs that should be appropriately addressed for effective instruction to take place (Kieran \& Anderson, 2019; Meyer, Rose, \& Gordon, 2014). Student teachers often have limited experiences in differentiation and need continuous support as they explore how to meet diverse students' needs in teaching (Guy, 2014; SantaMaria \& Thousand, 2004; Santangelo \& Tomlinson, 2012; Valencia, et al., 2009). Although pre-service teachers engage in discussion of differentiation, observation of teaching practices, and planning activities in taking methods courses (Yenmez \& Ozpinar, 2017), they have limited opportunities for classroom application (Dee, 2010; Tomlinson \& Imbeau, 2010) to meet diverse students' needs.

Research on manifestation of differentiated instruction for in-service elementary teachers is abundant from perspectives to evaluation of teacher practices (Coubergs, et al., 2017; De Neve \& Devos, 2016, 2017; SantaMaria, 2009; Tawil, 2014; Uribe, et al., 2019). Elementary teachers who had received training on DI recognized a need for continued professional development (Tawil, 2014). Some obstacles that hindered implementation of DI reported by the teachers were limited instructional time, lack of training, and lack of administrative support. Regardless, the majority of teachers held a favorable view of addressing challenges in diverse classrooms through application of differentiation.

Additionally, factors that had an impact on beginning teachers' participation in professional development activities on differentiation were studied (De Neve \& Devos, 2016, 2017). The findings (De Neve \& Devos, 2016) from the data analysis of 272 beginning teachers at 72 primary schools showed that the aspects of teachers' application included teacher education, reflective dialogue, and diversity in student population. It was concluded that the principal and the special need coordinator played a major role in the change of structural and cultural conditions of the schools. Based on the results, one educational implication was for teacher education 
programs to provide candidates with foundational knowledge of DI applications.

Differentiated instruction is an essential component in teacher education programs (D'Intino \& Wang, 2021). Research on pre-service teachers' practice of differentiated instruction in support of a variety of learners in a K-12 setting has been conducted across different programs (Brevik, et al., 2018; Dee, 2009; Guy 2014; Köksal \& Genç, 2019; Ochoa, 2013; Tulbure, 2011; Yenmez \& Ozpinar, 2017). Dee’s study (2009) examined how student teachers provided support to Grade 3-5 students of special education. The work samples were produced by 10 selected teacher candidates with five each from the undergraduate and graduate programs for a general education teaching credential. The themes emerged from the data analysis of the candidates included a tendency to use multiple intelligences and manipulatives for differentiation, a focus of reflection placed on the teacher rather than student learning, and very little evidence of meaningful planning for differentiation.

Other qualitative studies (Guy, 2014; Ochoa, 2013) highlighted how student teachers developed and applied differentiation through grouping and teamwork with mentor teachers. These case studies had a small sample size of three participants in each. One of the assertions from Guy's study (2014) was that student teachers' ability to handle differences in student learning needs was a major factor in transformation from a dependent teacher to an independent teacher. Pathway to successful practices of differentiation for the student teachers was directly affected by collaborative partnership with their mentor teachers.

Despite the attention given to differentiated instruction in teacher preparation, much is still needed in the research on effective pedagogical practices and classroom application for professional development (De Neve \& Devos, 2016; SantaMaria, 2009). This is especially so in the context of student teaching (Guy, 2014), a critical stage when teacher candidates are getting prepared for application of differentiation as an independent teacher in the near future.

In summary, application of differentiated instruction involves many components in content, process, products, and learning environment (Tomlinson, 2014), which is not linear or simple (Smets, 2017; Tomlinson, 1999). These aspects should be examined from a perspective of a teacher and perspective of students in their variance of needs and level of participation in learning. Student teachers' ability to meet diverse learning needs has a major impact on their professional development (Guy, 2014). Therefore, a study would be timely to investigate the professional development process including an initial overall plan for differentiation, teaching application in elementary classrooms, and summative reflection on areas for growth after student teaching. The summative reflection at the end of student teaching allows student teachers to re-examine teaching practices and plan next steps for their future students.

One of the challenges for the student teachers in this study was to make a transition from learning about differentiated instruction to application in elementary classrooms. Although differentiation was incorporated in the five subject specific methods courses (i.e., reading, English language arts, math, science, and social science), the pre-service teachers had limited opportunities to teach in elementary classrooms. These courses were taught on the university campus with 10 hours of required field experiences for observation in general.

In the context, two research questions were investigated: 1) How did the student teachers plan and apply differentiated instruction to support student learning? 2) How did the participants weigh differentiation in summative reflection on areas for growth after student teaching? In the first research question, English learners (ELs) were the focused group because the participants worked with these students in every assigned elementary classroom. In short, an English learner is a student with a primary language other than English, who needs support to develop English language proficiency to become successful in the school's regular instructional programs.

\section{Research Methods}

Data source triangulation and methodology triangulation (Johnson \& Christensen, 2019) were applied to data collection and analysis in this study. The examination of the student teachers' practices of DI was not in isolation but in the context of what they stated, planned, applied, and reflected on individually and collaboratively. Multiple sets or types of data including a survey, lesson plans, and after student teaching summative reflection were obtained during the process. Still other types of data such as informal and formal evaluations of student teaching and observation notes taken in various contexts were collected to analyze how the participants perceived and reflected on their practices aligned to the six standards for the teaching profession (California Commission on Teacher Credentialing, 2009). The student teachers also reflected on the weekly lessons they taught through debriefing with their mentor teacher and university supervisor. Therefore, multiple sets of data were obtained to examine the participants' practices and reflection from different angles to answer the two research questions.

\subsection{Participants}

The participants were 30 teacher candidates who were assigned to a K-5 classroom to fulfill the student teaching requirements. They were each assigned to work with a mentor teacher to follow their full time school and 
teaching schedule. The student teachers gradually phased in by picking up teaching and non-teaching tasks until they were in full responsibilities for at least two weeks.

Before student teachers reported to their assigned school, they discussed differentiation during the student teaching orientation. They watched a video lesson that featured how a teacher applied differentiated instruction to facilitate learning and analyzed the strengths and areas to improve. Next, they shared their analysis of the lesson by participating in discussion as a small group and then as a whole class. To establish a common ground, the student teachers reviewed the strategies for teaching ELs (Herrell \& Jordan, 2019). As a follow-up, they reviewed and critiqued a sample lesson plan including a component of differentiated instruction to get prepared for lesson planning and teaching in the classrooms. Moreover, the participants understood that they were to pass a state mandated assessment by using information and data collected during student teaching. In the assessment, differentiation for English learners and two other types of learners was required.

One of the main tasks for the student teachers was to plan instruction across different subjects, and they were expected to support students in content and literacy development. They designed lesson plans and taught the lessons to meet diverse student needs. They taught a lesson for observation once a week during weeks 4-7 of student teaching. They also wrote weekly journals to reflect on their teaching practices and participated in debriefing with their mentor teacher and university supervisor after teaching a lesson. At the end of 15 weeks of student teaching, the participants self-evaluated and reflected on strengths and areas to improve as a credentialed teacher in the future.

\subsection{Data Collection}

Different types of data were collected at different times of student teaching. The primary data sets collected from the participants were their responses to a survey, four lesson plans, and summative reflection on what to improve after student teaching. Other types of data included observation notes of the participants during the orientation, lesson delivery, debriefings, and other meetings in addition to student teaching evaluations. Details about the three primary data sets collected in sequence are as follows.

First, during the third week of student teaching, the participants completed a survey to share their overall plan to support all students, including ELs in an inclusive classroom. In their responses, they also explained why they selected certain strategies or why they believed the strategies were appropriate to support the identified students.

Next, the student teachers developed lesson plans on different subjects for four consecutive weeks from the fourth week of student teaching. One of the components in the lesson plan template was "Differentiated Instruction" to support diverse students. After reviewing differentiation strategies (Herrell \& Jordan, 2019) at the student teaching orientation, all participants had access to the same list. A total of 120 lesson plans written by the student teachers were collected.

The last set of data was obtained at the end of student teaching when the participants did summative reflection on strengths and areas for growth as a beginning teacher in the future. Each of them highlighted three areas to improve after student teaching for professional development.

\subsection{Statistical/Data Processing Methods}

Both qualitative and quantitative data were analyzed to answer the research questions. Qualitative data analysis featured a cyclical and iterative coding process to be segmented and labeled with En Vivo. Quantitative data of the survey responses or lesson plans emerged when frequency of themes or strategies was summarized. A figure with a bar graph was made to compare the themes found in the survey responses and lesson plans by percentage to reveal any similarities or differences. Themes with frequency of participants' summative reflection done at the end of student teaching were also coded, organized, and encapsulated for analysis and discussion.

Other types of data such as observation notes of lessons were attained to examine how the lesson plans were executed in teaching. Weekly reflection journals and evaluations of student teachers were also reviewed to analyze the participants' practices in the context. Finally, data was coded and themes were identified and summarized by two data processors. Inter-rater reliability of at least .87 was obtained to maintain consistency and accuracy in coding and theme identification.

\section{Data Analysis and Results}

Themes were identified through an analysis of the three types of primary data in reference to the list of differentiation strategies (Herrell \& Jodan, 2019) as appropriate. Some participants precisely used a strategy name such as Visual Scaffolding, while others selected relevant words (e.g., "pictures/illustrations in a book", "flash pictures/cards", "pictures", "video clips", "slides", "place value chart", or "maps") to describe the same strategy. Any strategies or ideas that a participant included in the survey responses were identified, coded, and counted once.

In each of the four lesson plans written by the student teachers, the "Differentiation Instruction" section was 
analyzed and recorded. If any participants overlooked this component in a lesson plan, they were asked to fill it out. The group included approximately three strategies in each of their lesson plans on average. Moreover, when the participants did summative reflection, they were free to select any aspects based on their student teaching experiences. When they chose to cover differentiated instruction, it was not because they were asked to do so but because they wanted to highlight the area for improvement as future teachers.

\subsection{Research Question 1: Application of Differentiation}

Table 1 is a summary of what the participants included in their responses to the survey and lesson plans. They responded to the survey to present an initial plan of supporting all students including English learners. They completed the survey before teaching the first of the four lessons, so the responses were primarily a reflection of their prior experiences or prior learning of differentiation. Data summary of the survey responses and the lesson plans is displayed in Table 1.

Other than the strategies included in the book (Herrell \& Jordan, 2019), "Sentence Stems" was added to Table 1 based on the description, explanation or application. The participants provided 13 different strategies or ways in total to address differentiation, and seven of them were highlighted due to a higher level of frequency for both data sets. At the bottom of the Table 1, "Others" comprised a list of strategies each with a frequency lower than four in any of the data sets.

Table 1: Summary of the Survey Responses and Lesson Plans: Strategies and Frequency

\begin{tabular}{|c|c|c|}
\hline Strategies & Description or Examples & Survey/ LP \\
\hline Visual Scaffolding & $\begin{array}{l}\text { Create a meaningful context for learning with } \\
\text { pictures/illustrations, photos, video clips or slides }\end{array}$ & $20 / 89$ \\
\hline $\begin{array}{l}\text { Preview/Review } \\
\text { (Vocabulary) }\end{array}$ & $\begin{array}{l}\text { Guide students to study vocabulary before, during and after a lesson } \\
\text { through pronunciation, labeling, word analysis or organizing words } \\
\text { for application }\end{array}$ & $14 / 75$ \\
\hline $\begin{array}{l}\text { Small Groups and } \\
\text { Partners }\end{array}$ & $\begin{array}{l}\text { Generate collaborative learning among or between students for oral } \\
\text { language, literacy, and content development }\end{array}$ & $18 / 43$ \\
\hline Graphic organizers & $\begin{array}{l}\text { Visually represent ideas, text, and connections between texts } \\
\text { in a format, e.g., a flow chart to show sequence of events }\end{array}$ & $10 / 28$ \\
\hline Sentence Stems & $\begin{array}{l}\text { Provide a structure to meet students' needs by using sentence frames } \\
\text { or sentence starters }\end{array}$ & $11 / 19$ \\
\hline Manipulatives & $\begin{array}{l}\text { Use items such as cubes, beans, fluffballs for hands on activities to } \\
\text { study concepts }\end{array}$ & $4 / 9$ \\
\hline Realia & $\begin{array}{l}\text { Facilitate understanding/learning with real objects such as plants, } \\
\text { household items, and animals }\end{array}$ & $6 / 6$ \\
\hline $\begin{array}{l}\text { Leveled } \\
\text { Questions }\end{array}$ & $\begin{array}{l}\text { Adjust questioning strategies in response to the level of students to } \\
\text { engage and guide them in learning }\end{array}$ & $4 / 24$ \\
\hline $\begin{array}{l}\text { Total Physical Response } \\
\text { (TPR) }\end{array}$ & $\begin{array}{l}\text { Use physical gestures, hand motions or actions to facilitate } \\
\text { communication and support learning }\end{array}$ & $2 / 8$ \\
\hline Others & $\begin{array}{l}\text { Slow speech, allowing thinking time, audio to support reading, use } \\
\text { of students' primary language, and text at students' level }\end{array}$ & $10 / 10$ \\
\hline Total & & $99 / 311$ \\
\hline
\end{tabular}

The participants responded to the survey, sharing their plan of differentiation to meet student needs. Many participants selected the same strategies, and the total of strategies proposed by the entire group was 99 across 13 types. Below is a sample that one of the participants planned after describing the needs of an English learner:

I plan to pull her into a group for targeted, small group instruction in which we will preview both academic vocabulary and key words/phrases for upcoming lessons. Putting up anchor charts with key information and sentence stems will also help this student participate in discussions with partners, small groups, and the whole class. Furthermore, I plan to incorporate more total physical response across all content areas - especially math which is very loaded with academic vocabulary - so that focus student 1 (an EL) has another device to help her study concepts.

The participant designed differentiation by incorporating several strategies to facilitate learning of the English learner. The plan had an emphasis on using different strategies to support academic language development in different subjects. The sample response signified that the participant learned about the strategies and was ready to work with the student in application.

Despite individual differences, the participants had an opportunity to tap into their prior knowledge acquired in taking the methods courses (Yenmez \& Ozpinar, 2017). Application of strategies should respond to many factors such as grade level, student needs, and subject matter in addition to each participant's prior nonteaching or teaching experiences. A challenge for the student teachers was to adapt teaching based on 
participation and learning outcomes of students. They would soon find out if their plan was appropriately designed to meet their students' needs.

When the participants planned and taught lessons, they had opportunities to develop ability by examining details of student learning. Table 1 also displayed the frequency of all themes or strategies that the student teachers specified or listed in their lesson plans with a total of 311 distributed over 13 different themes/strategies. The strategies found in the lesson plans and the survey responses were generally identical except differences in frequency. The student teachers were free to choose any strategy in designing any of the four lesson plans.

Despite the individual differences, the paired data sets (see Table 1) noted that the group preferred to use some strategies much more than others in the survey responses or lesson plans. The most frequently selected or used strategy in both sets was Visual Scaffolding with 20 out of $99(20 \%)$ for the survey and 89 out of $311(28 \%)$ for the lesson plans. To make it easier for data review or comparison, Figure 1 presents a graph of the two data sets by percentage.

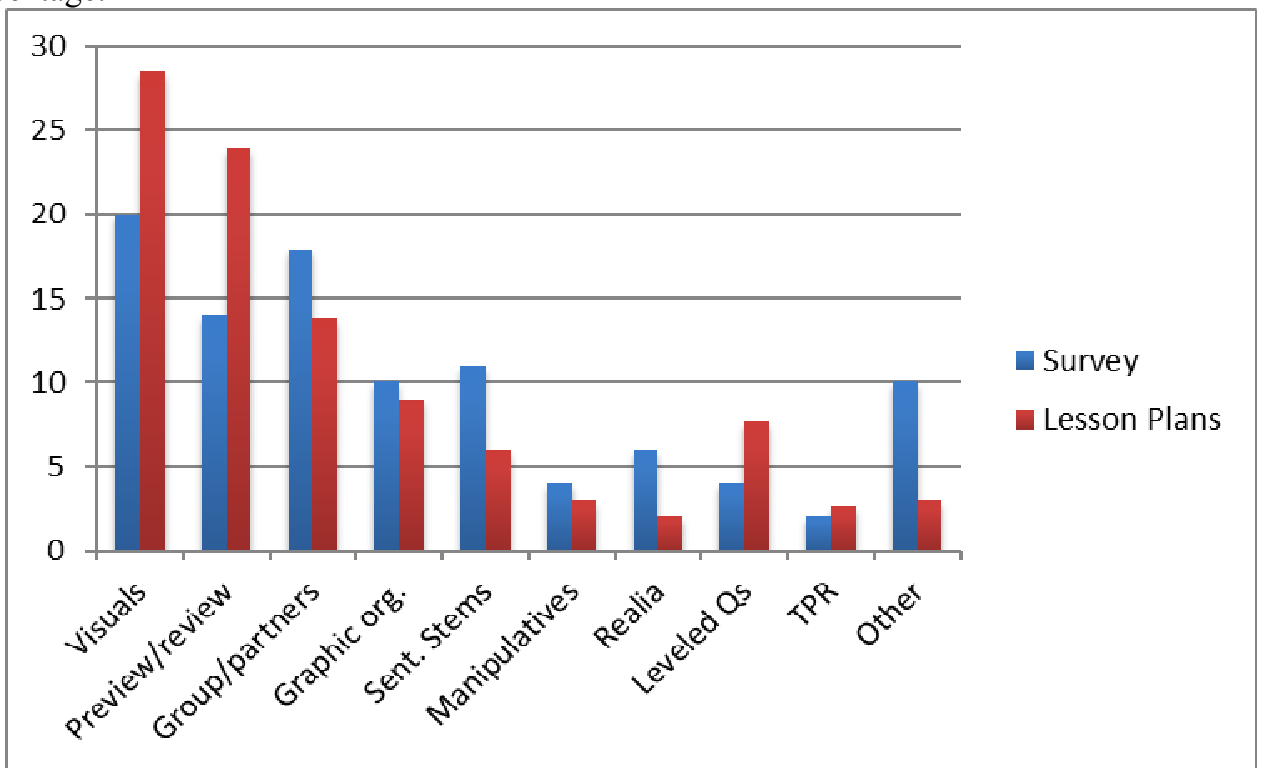

Figure 1: Summary of Themes in the Survey Responses/Lessons Plans by Percentage

The prevalent attention given to Visual Scaffolding was well manifested in a student teacher's survey response:

I will heavily reference and use visual depictions of concepts that I am teaching in any given subject, often making use of pictures, step-by-step drawing (polygons on graph paper), anchor charts, etc. to help students visualize and make connections to prior knowledge when being introduced to concepts in these lessons.

The above response specified a plan of using visuals in a variety of ways to address multiple means of representation (Meyer, Rose, \& Gordon, 2014) to help students build connections between prior knowledge and a new concept in a meaningful context for learning. The participants' highlight of using visuals such as pictures or video clips was confirmed in the lesson plans and observations. Nevertheless, their plans to "help students" showed that the student teachers primarily approached differentiation from a teacher perspective (Dee, 2009), with limited attention given to a student perspective or details about student participation or demonstration of learning during instruction.

Although Visual Scaffolding was the most frequently considered or used strategy, the participants' classroom application varied. The impact of application on student learning was also different due to the participants' individual differences or change/growth over time. Two examples below serve to illustrate some differences in the application.

In Case 1, a student teacher applied Visual Scaffolding by selecting a picture of a ship in hope to support students in text analysis. However, since the text focus was on the use of technology (e.g., gunpowder and compass) in the expeditions, the picture of a ship alone did not really help students comprehend the assigned reading text or understand the featured technologies. Moreover, the participant did not use an excerpt to discuss expectations or provide guidance in reading and check for understanding before assigning the group activity. As a result, she had to spend time answering the students' questions about expectations or participation. The students were not prepared for doing teamwork, and the student teacher recognized an area to improve in providing direct instruction and guidance. Teacher facilitation (Westman, 2018) is a critical element in application of differentiation so that students can receive appropriate support in learning (Vygotsky, 1978).

In Case 2 of applying Visual Scaffolding, the student teacher showed differences in teacher-student 
interaction and student participation. She engaged students in learning by using pictures, anchor charts, and vocabulary to present and discuss the concept of water cycle. During the lesson, she addressed student participation by having them use mini whiteboards to draw, label, and write to demonstrate what they knew or learned. She monitored student learning based on their oral/written responses and used the results to adjust instruction. She also had some students present their sample work to generate discussion for clarification or highlights and promote student collaboration.

It is important to study different ways of differentiation, but the ultimate goal is that pre-service teachers develop teaching ability. Attention to details in lesson planning and actions taken during a lesson have a direct impact on the quality of differentiated instruction. In the context, it is one thing to choose pictures or visuals but it is quite another to present appropriate visuals to engage and support students. If the focus is placed on the "teacher" or "student teacher", it would be challenging for meaningful planning to take place (Dee, 2009) without checking details about student learning. The level of student participation affects students' demonstration of learning outcomes. Therefore, a teacher needs to provide facilitation, monitor student learning, and use the collected data (Meyer, Rose, \& Gordon, 2014; Tomlinson, 2014) to evaluate what worked and did not work to inform instruction.

The next two most frequently highlighted strategies on the list of survey responses and lesson plans were Preview/Review of vocabulary and Small Group/Partners (see Figure 1). Although differences ranged between $13 \%$ and $24 \%$ for the sets of data, each of the four figures was higher than any others on the graph.

For Preview/Review of vocabulary, the participants as a group included it in lesson planning and teaching (24\%) much more than they had originally planned (14\%) in their survey responses. One important aspect for English learners is to develop academic language so that they can process reading text of different subjects and demonstrate learning through language output. Key words are basic blocks for students to develop academic language about concepts. For example, in studying "Earth and the Solar System", students need to learn the concept by using key vocabulary such as "orbit", "rotation", and "axis". Through applying the words in a meaningful context with pictures, charts, or labeled drawings, a teacher can facilitate learning, and students can participate and demonstrate learning.

Similar to the practice of Visual Scaffolding, the participants' application of Preview/Review of vocabulary also showed differences. A number of student teachers introduced key vocabulary at the beginning of a lesson by modeling pronunciation and had students copy the words and/or definitions. As the lesson continued, the words were not revisited or discussed for clarification or reinforcement, and students did not get a chance to demonstrate learning by using the words. In comparison, some other participants prepared a poster of key vocabulary including graphic organizers and labeling for use and reference to facilitate learning during a lesson. They also organized activities for students to use the words and/or definition to answer questions orally and through writing.

In addition, differences were found in the number of selected key vocabulary for a lesson, ranging from one word to eighteen. One word appears insufficient for students to reveal their learning about a concept, while eighteen words can be overwhelming to learn and grasp in one lesson. Also, discrepancy surfaced between key vocabulary specified in a lesson plan and what was actually presented to students in the teaching of a lesson. So, how to select vocabulary to teach a concept in a lesson was discussed in debriefing. Attention to details such as vocabulary selection, number of words to include, and organizing activities in a lesson should not be overlooked in lesson planning and teaching. To address issues, the observed practice or change of practice in a lesson was discussed in debriefing to explore alternatives to improve instruction through professional teamwork (Guy, 2014; Ochoa, 2013). The progress that the student teachers made also varied when some needed more time to turn an area for growth into a strength than others in applying differentiation. Factors contributing to the differences may include individual participants' ability to adapt and level of student diversity in elementary classrooms (De Neve $\&$ Devos, 2016). The student teachers were more challenged to differentiate instruction when they had a wider range of student needs to meet.

Unlike what happened to Preview/Review of vocabulary (see Figure 1), the participants applied Small Groups and Partners in the lessons (18\%) more than what they anticipated in the survey responses $(13 \%)$. Observation of teaching also verified that participants' application diverged in the types of teamwork, time allotment, and student responsibilities. For instance, students were assigned to collaborate with an elbow partner, in a group by mixed ability, and/or in a group by the same reading level/proficiency level. Also, frequency of assigning collaborative work in a lesson ranged from once to multiple times. Sometimes, some participants focused on group/partner work in a lesson and did not have students demonstrate learning independently at all. If students did not have any opportunity to produce any sample work independently, a teacher would be challenged to evaluate whether each of students reached learning goals or what support they still needed.

Moreover, the participants showed differences in how they addressed student responsibilities in collaboration. Some student teachers provided simple directions such as "Talk to your elbow partner". Others presented and discussed written directions with specific tasks assigned to each member of a team. Also, some 
only instructed students to participate orally or voluntarily, but others had students produce written work to hold everyone responsible. The student written samples consequently became part of assessment data. Additionally, student participation in teamwork was not balanced in some cases when advanced students were only expected to assist others. How advanced students could have benefited from participating in a collaborative activity should also be addressed in differentiation.

Therefore, the findings in this study validated that it is a complex process for student teachers to develop competency in applying differentiated instruction (Smets, 2017; Tomlinson, 1999) because many aspects and details are involved in planning and delivering lessons. The participants had an opportunity to reflect on their teaching practices through debriefing with their mentor teacher and university supervisor. By discussing a lesson planned and taught by a student teacher, the members participated in reflection through teamwork (Guy, 2014; Ochoa, 2013). The goal of collaborative reflection was to analyze strengths and areas of needs for the student teachers to continue doing what worked effectively and make changes for improvement. In doing so, they practiced deep reflective thinking and problem solving (Lee, 2005; Liu, 2022) and were able to build stamina in the process. The most effective student teachers were the ones who were enthusiastic and efficient in taking actions to change areas for growth into strengths. Unlike their counterparts (Dee, 2009; Köksal \& Genç, 2019), the participants in the current study learned to address meaningful planning for differentiation through reflection and debriefing on their teaching practices about what worked or did not work and what could have been done differently. They had opportunities to examine details in planning and teaching lessons to create a learning community and promote student participation.

\subsection{Research Question 2: Professional Development on DI After Student Teaching}

At the end of student teaching, all participants completed summative reflection on the areas that they wanted to improve in induction. They selected three areas of needs for continued professional development based on their student teaching experiences. The criteria they observed in the reflection were the six standards for the teaching profession (California Commission on Teacher Credentialing, 2009) with differentiated instruction integrated. The participants chose or formed a subtitle for each area to improve, followed by a paragraph for elaboration. In preparation for the summative reflection, the participants reviewed all information and documents they had produced, collected or received during student teaching including weekly reflection journals, lesson plans, student samples, and evaluations from their mentor teacher and university supervisor. Although they were encouraged to discuss areas for growth with the support team, it was up to a student teacher to make a decision. In other words, the participants were not asked to give special attention to any particular area such as differentiated instruction unless they voluntarily chose to do so. Among the six professional standards, Standard 3 includes "3.6 Addressing the needs of English learners and students with special needs to provide equitable access to content," in which "English learners" is stipulated. Despite that, reflection on any other standards could be related to differentiation.

The results showed that a major area for growth highlighted by the participants was to support students of diverse needs although no particular group such as ELs was highlighted (see Table 2). The theme of differentiation was found in 53 out of 90 areas for professional growth, which they provided collectively. Table 2 is a summary of what the participants would like to improve in differentiated instruction after student teaching by themes, examples, and frequency.

Table 2: Summative reflection on areas to improve in DI after student teaching

\begin{tabular}{lll}
\hline Aspects & Description or Examples & $\#$ \\
\hline $\begin{array}{l}\text { Assessments of student } \\
\text { learning }\end{array}$ & $\begin{array}{l}\text { Use assessment means to collect data, have students demonstrate } \\
\text { learning in different ways, guide students in self-assessment, } \\
\text { communicate progress with students and family, promote student } \\
\text { ownership, and redirect instruction based on assessment data }\end{array}$ & 20 \\
$\begin{array}{l}\text { Apply other DI } \\
\text { strategies }\end{array}$ & $\begin{array}{l}\text { Further explore how to apply technology, create a print rich } \\
\text { environment, support reading/writing development, help students who } \\
\text { fall behind catch up, use graphic organizers, and engage students in } \\
\text { collaborative learning }\end{array}$ & 16 \\
$\begin{array}{l}\text { Make learning meaningful by relating to student life experiences and } \\
\text { interests and prior } \\
\text { learning or background } \\
\text { Students with different } \\
\text { types of needs }\end{array}$ & $\begin{array}{l}\text { Gain more experiences in working with learners such as advanced } \\
\text { students, beginning English Learners, students who miss part of } \\
\text { instruction due to absence or pull out }\end{array}$ \\
$\begin{array}{l}\text { Set up goals based on } \\
\text { student needs }\end{array}$ & $\begin{array}{l}\text { Tailor learning goals to support content and academic language } \\
\text { development in response to students' needs }\end{array}$ & 7 \\
\hline
\end{tabular}


The findings confirmed the need expressed by the elementary teachers for professional development to meet diverse students' needs (Tawil, 2014). The participants in the current study should be perceived as beginning elementary teachers since they did the summative reflection at the end of student teaching. Their highlight of differentiation strategies included using technology and creating a print-rich environment to facilitate learning. They also gave attention to integration of reading and writing and applying thinking maps/graphic organizers to help students process information or demonstrate learning. They wanted to facilitate group work among students through flexible grouping and help those students in need catch up, as one student teacher wrote:

During student teaching I worked with beginning English learners to Excel students. I want to improve in this area so that all my students' needs are met individually. A specific differentiation strategy I want to improve in is forming small, flexible groups based on students' similar needs.

The participant worked with students of diverse needs as a student teacher. Based on the experiences, he wanted to know each of his future students as individuals. To reach the goal, on-going assessment (Hall, 2002; Tomlinson, 2014) is needed to plan and organize appropriate group activities for students with similar needs.

The above student teacher represented the group to plan next steps by building on student teaching practices of applying strategies such as Small Groups and Partners as shown in Table 1. However, other strategies (e.g., Realia, Manipulatives, and Total Physical Response) listed in Table 1 did not emerge in the summative reflection. A major difference shown in Table 2 as compared to Table 1 was that "assessments" had the highest frequency with 20 out of 53 in total on differentiation. This can be an indicator that the participants, after completing student teaching, moved to a higher level of applying differentiation with attention directed to student demonstration of learning. A plan of differentiation can only be meaningful when it is designed to meet students' needs, and a teacher gets to know student learning through doing assessments. Subsequently, the student teachers shifted the focus from designing a lesson plan based on their foundational knowledge of differentiation to assessing students' strengths and needs and using the data to inform instruction.

Although "Checking for Understanding" was one of the strategies (Herrell \& Jordan, 2019), "assessments" was separately listed (see Table 2) due to its highest frequency and meaning. Based on the participants' sample work, assessments meant not only progress monitoring during a lesson but also formal assessment and student self-assessment. Although assessing students for learning was the focus of Standard 5, the participants made connections to assessments in choosing and describing areas for growth across different professional standards. For example, a student teacher provided the following under a title of "Standard 2.7 Using instructional time to optimize learning":

The importance of keeping the mini-lessons between 15 and 20 minutes is to provide more time for students to practice the skills taught and to encourage more self-directed learning. When the lessons are shorter, it allows for the teacher to meet up with groups to confer and record evidence of the students' learning and use the data to make adjustments in teaching.

In the above case, collecting and using assessment data was discussed in the context of organizing group activities for differentiation and increasing efficiency of instructional time. The student teacher intended to improve the quality of direct instruction (Westman, 2018), allot time to interact with students, and have them demonstrate learning. Data collection about student learning must be secured for decision making before changes can be made to improve teaching.

The results implied that the participants became aware of the importance of conducting assessments and using assessment data to evaluate the quality of instruction. They wanted to further explore how to use assessment data to check if diverse students reached learning goals. What one student teacher expressed can serve as an example in the context: "I also need to improve in my knowledge and application of a variety of effective assessment strategies to allow diverse learners a variety of ways to demonstrate achievement of learning goals." This suggested a change of focus from a teacher perspective to active student participation and demonstration of learning through multiple means of action and expression (Meyer, Rose, \& Gordon, 2014). The aforementioned comment was echoed in the following quote when another participant observed the importance of conducting assessments, using assessment data to drive instruction, and treating students respectfully as team members.

I should have done more assessments of my students and actually use them more to plan my lessons. I would simply collect students' work, grade, and then move on to the next lesson. I want to consistently use student assessments to monitor my students' progress. In addition, I can strengthen my teaching by basing it on how my students can learn most effectively rather than how I want them to learn.

The above student teacher wanted to not only do more comprehensive data collection but also further develop in consistently using data to evaluate student learning and improve teaching. Also, she wanted to accept and value students as stakeholders in the learning community. Instruction should be designed to help students learn most effectively under the support of a teacher (Vygotsky, 1978). In the meantime, students should be treated as respected team members instead of passive receivers of knowledge in the instructional dynamics. 
Furthermore, the student teachers hoped to get their students involved in self-assessment along with goal setting and self-progress monitoring as active learners. They would like to facilitate students' exploration in learning by starting from where they were. The goal was to "prepare students to be their own teacher, for students to take ownership in their education", as a student teacher expressed. In doing so, the participants took an important step to acknowledge both teachers and students as stakeholders (Kluth \& Chadler-Olcott, 2017; Westman, 2018). Active student participation and teamwork of both parties should be addressed for effective teaching and learning to take place. To develop abilities in self-study and self-assessment, students learn to think actively or critically and become active and contributing members of a learning community.

\section{Implications}

The participants began exploration of differentiated instruction when taking methods courses prior to student teaching. By building foundational knowledge of differentiation (Yenmez \& Ozpinar, 2017), the student teachers had a "toolbox" accessible for planning and teaching lessons. However, pre-service teachers can hardly evaluate their understanding of differentiation until they teach lessons and monitor student learning in elementary classrooms. Therefore, teacher preparation programs should consider increasing opportunities for classroom application (Dee, 2010; Tomlinson \& Imbeau, 2010) to enhance teacher candidates' professional development. By analyzing what worked or did not work in teaching, candidates get to know elementary students' strengths and needs in learning before exploring what to do next. Such experiences can make a difference in preparing preservice teachers for student teaching and transformation to an independent teacher (Guy, 2014).

Teacher candidates grow professionally when they reflect to make decisions and resolve issues (Lee, 2005; Liu, 2022). The participants learned that applying Visual Scaffolding meant much more than choosing pictures. The most critical part was to organize and use the selected visuals appropriately to create a meaningful context to support student learning. Teacher candidates develop teaching ability when they are able to evaluate their plan of differentiation through working with students of diverse needs. The process creates opportunities for reflective thinking (Lee, 2005) through application of collaborative and independent reflection. Teacher candidates become more competent through learning to address issues and solve problems (Liu, 2022).

By planning and teaching lessons followed by reflection, the participants realized how important it was to collect assessment data and monitor student learning during instruction. On-going assessment of student learning is a critical and inseparable part of differentiated instruction (Hall, 2002; Meyer, Rose, \& Gordon, 2014; Tomlinson, 2014). In other words, pre-service teachers are not able to assess learning until they implement a lesson plan in elementary classrooms. They need to collect assessment data by observing student participation and analyze learning outcomes to uncover if objectives are reached. This explains why the participants wanted to further develop in assessments when planning for induction at the end of student teaching. They also learned that assessments meant more than what teachers know and do because students should be active learners and develop ability in self-study and self-assessment.

The findings indicated that the student teachers highlighted a need to further develop in attending details about student action and expression (Meyer, Rose, \& Gordon, 2014), after practicing differentiation during student teaching. By re-evaluating how a student teacher and students had interacted, collaborated, and contributed to effective instruction, the participants preferred to adopt a model of engaging their students as active learners. When students are able to actively participate in learning, their motivation should be at a different level, and a teacher can also obtain more useful information about individual students. A student teacher's ability to collect and use comprehensive assessment data to redirect teaching as appropriate affects the quality of instruction. Therefore, student teachers should be guided to promote student active participation including demonstration of learning and student ownership when they design and teach lessons with differentiation. How and when comprehensive assessments should be addressed during student teaching can be another area for teacher education programs to explore.

Finally, the scope of this study is not all-encompassing. The examination of the K-5 student teachers excluded differences in grade level or subject matter. Other aspects to further study may involve the process of student teachers' decision making and relationship between assessments and subsequent actions taken to redirect instruction. Therefore, future research studies are desirable to analyze student teachers' practice of differentiated instruction more in-depth, in detail or in evolution. For example, what instructional strategies can be most effectively used to meet students' needs in a certain grade level for the teaching of a subject? Additionally, an investigation of how student teachers conduct assessments and use assessment data to adjust instruction might lead to new insight about student teachers' professional development. Such new results should be valuable to both researchers and teacher educators to better understand the topic and improve the quality of teacher preparation.

\section{Conclusion}

Teacher candidates build foundational knowledge of differentiation when they engage in discussion of the 
concept in methods courses. Nevertheless, they need to follow up with classroom application to grow and develop teaching competence. By working with elementary students, they can execute the concept or strategies to meet diverse students' needs through decision making and problem solving. It is an important step to get to know students or their learning so that student teachers can make decisions to help students reach learning goals. Student teachers or teachers must be prepared to consistently make adjustments because student needs and strengths can be different due to many factors such as subject matter, language proficiency, behavior or time and places in the teaching and learning dynamics. To evaluate the quality of teaching, teachers must create opportunities for students to demonstrate learning through action and expression in different contexts.

An important way to get to know students and facilitate learning was through interacting with them, collecting assessment data, and using the data to make adjustments. Additionally, assessing learning means more than what a student teacher can do because students should actively participate and self-direct in learning. Practice of student self-assessment or self-study requires active student engagement, can promote higher-order thinking, and makes it possible for teachers to collect more comprehensive and accurate assessment data about individual students. The sooner the gap between the foundational knowledge of differentiation and application in elementary classrooms is bridged, the sooner teacher candidates can move to a higher level in professional development. Transformation from a dependent to an independent teacher should involve knowledge of differentiated instruction, teaching application in the classroom, and comprehensive assessments through teacher-student teamwork in addition to on-going deep level independent and collaborative reflection.

\section{References}

Brevik, L. M., Gunnulfsen, A. E., \& Renzulli, J. S. (2018). Student teachers' practice and experience with differentiated instruction for students with higher learning potential. Teaching and Teacher Education, 71, 34-45.

California Commission on Teacher Credentialing (2009). California Standards for the Teaching Profession. Commission on Teacher Credentialing.

Coubergs, C., Struyven, K., Vanthournout, G., \& Engels, N. (2017) Measuring teachers' perceptions about differentiated instruction: The DI-Quest instrument and model. Studies in Educational Evaluation, 53 (4154).

D'Intino, J. S. \& Wang, L. (2021). Differentiated instruction: A review of teacher education practices for Canadian pre-service elementary school teachers. Journal of Education for Teaching, DOI: $10.1080 / 02607476.2021 .1951603$

De Neve, D. \& Devos, G. (2016). The role of environmental factors in beginning teachers' professional learning related to differentiated instruction. School Effectiveness and School Improvement, 27(4), 357-379.

De Neve, D. \& Devos, G. (2017). How do professional learning communities aid and hamper professional learning of beginning teachers' professional learning related to differentiated instruction? Teachers and Teaching: Theory and Practice, 23(3), 262-283.

Dee, A. L. (2009). Differentiated instruction in the work sample: A study of preservice teacher practice. Faculty Publications - School of Education. 17. http://digitalcommons.georgefox.edu/soe_faculty/17

Dee, A. L. (2010). Preservice teacher application of differentiated instruction. The Teacher Educator, 46(1), 5370.

Gardner, H. (1999). The disciplined mind: What all students should understand. New York: Simon and Schuster.

Guy, L. D. (2014). Differentiated instruction for responsive teaching in elementary education student teachers' classrooms (Publication No. 3681080) [Doctoral dissertation, University of North Dakota]. Proquest Dissertations and Theses database.

Hall, T. (2002). Differentiated instruction. Effective classroom practices report. National Center on Accessing the General Curriculum, CAST, U.S. Office of Special Education Programs.

Herrell, A., \& Jordan, M. (2019). Fifty strategies for teaching English language learners (6 ${ }^{\text {th }}$ edition). Pearson.

Johnson, B. \& Christensen, L. (2019). Educational research: Quantitative, qualitative and mixed approaches ( $7^{\text {th }}$ edition). Sage.

Kieran, L. \& Anderson, C. (2019). Connecting Universal Design for Learning with culturally responsive teaching. Education and Urban Society, 51(9), 1202-1216.

Kluth, P. \& Chandler-Olcott, K. (2017). Inclusive literacy learning. Reading Rockets. https://www.readingrockets.org/article/inclusive-literacy-learning

Köksal, D., \& Genç, G. (2019). Learning while teaching: Student teachers' reflections on their teaching practicum. Journal of Language and Linguistic Studies, 15(3), 895-913.

Lee, H. J. (2005). Understanding and assessing preservice teachers' reflective thinking. Teaching and Teacher Education, 21(6), 699-715

Liu, P. (2022). Reflection in alignment to professional standards: What did the student teachers highlight? Journal of Global Education and Research, 6(1), 67-81. 
Meyer, A., Rose, D. H., \& Gordon, D. (2014). Universal design for learning: Theory and practice. CAST.

Ochoa, B. R. (2013). Preparing preservice teacher candidates to differentiate instructional practices (Publication No. 3610309) [Doctoral dissertation, Baylor University]. Proquest Dissertations and Theses database.

SantaMaria, L. J. (2009). Culturally responsive differentiated instruction: Narrowing gaps between best pedagogical practices benefiting all learners. Teachers College Record, 111(1), 214-247.

SantaMaria, L. J., \& Thousand, J. S. (2004). Collaboration, co-teaching, and differentiated instruction: A process-oriented approach to whole schooling. International Journal of Whole Schooling, 1(1), 1-35.

Santangelo, T., \& Tomlinson, C. A. (2012). Teacher educators' perceptions and use of differentiated instruction practices: An exploratory investigation. Action in Teacher Education, 34, 309-327.

Smets, W. (2017). High quality differentiated instruction - A checklist for teacher professional development on handling differences in general education classroom. Universal Journal of Educational Research, 5(11): 2074-2080.

Tawil, S. (2014). Differentiated instruction at the elementary level: Teaching to a diverse student population. (Publication No. 3621423) [Doctoral dissertation, Northcentral University]. Proquest Dissertations and Theses database.

Taylor, S. (2017). Contested knowledge: A critical review of the concept of differentiation in teaching and learning. Warwick Journal of Education, 1, 55-68.

Tomlinson, C. A. (1999). Leadership for differentiated classrooms. The School Administrator, 56(9), 6-11.

Tomlinson, C. A. (2014). The differentiated classroom: Responding to the needs of all learners ( $2^{\text {nd }}$ edition). ASCD.

Tomlinson, C. A., \& Imbeau, M. B. (2010). Leading and managing a differentiated classroom. ASCD.

Tomlinson, C. A., \& Kalbfleisch, M. L. (1998). Teach me, teach my brain: A call for differentiated classrooms. Educational Leadership, 56(3), 52-55.

Tulbure, C. (2011). Differentiated instruction for pre-service teachers: An experimental investigation. Social and Behavioral Sciences, 30, 448-452.

Uribe-Zarain, X., Liang, J., Sottile, J., \& Watson, G. R. (2019). Differences in perceived issues in teacher preparation between first year teachers and their principals. Mid-Western Educational Researcher, 31(4), 407-433.

Valencia, S. W., Martin, S. D., Place, N. A., \& Grossman, P. (2009). Complex interactions in student teaching: Lost opportunities for learning. Journal of Teacher Education, 60(3), 304-322.

Vygotsky, L. S. (1978). Mind in society: The development of higher psychological processes. Harvard University Press.

Westman, L. (2018). Succeeding in differentiation. Edutopia. https://www.edutopia.org/article/succeedingdifferentiation

Yenmez, A. \& Ozpinar, I. (2017). Pre-service education on differentiated instruction: Elementary teacher candidates' competencies and opinions on the process. Journal of Education and Practice, 8(5), 87-93. 